\title{
Strategy Comparison of Power Ramp Rate Control for Photovoltaic Systems
}

\author{
Dingyi Lin, Xingshuo Li, Shuye Ding, and Yang Du
}

\begin{abstract}
The high variability rate of solar irradiance can lead to fluctuations in the photovoltaic (PV) power generation. Consequently, it will bring severe challenges to the stable operation of the power grid. In order to mitigate those problems, the power ramp rate control (PRRC) is required by some utilities. Generally, the PRRC can be achieved by using two methods: energy storage systems (ESS) or active power curtailment. However, there is a lack of comparison of those methods on economic performance. Usually, the levelized cost of energy (LCOE) index is adopted to quantify and compare the cost for different methods. In previous work, an ideal value of ESS lifetime is mostly set to analyze the LCOE. However, the different ESS methods may require the battery to operate at different regimes (i.e., number of cycles and depth of discharger), which directly affects the lifetime. Thus, the battery aging is necessarily introduced to compare the LCOE. In order to fill this gap, this work demonstrates an evaluation of aging through the annual simulations using actual irradiance data. This is done for the LCOE of different PRRCs to determine which is the most cost-effective method.
\end{abstract}

Index Terms-Active power curtailment, energy storage system, levelized cost of energy, photovoltaic (PV) energy, power ramp rate control.

\section{INTRODUCTION}

$\mathrm{I}$ $\mathrm{N}$ recent years, the solar photovoltaic (PV) generation increases significantly among renewable generations. Since PV generation is affected by weather conditions, it causes high variations to the injected power [1], [2]. As the penetration of solar energy is increased, it will bring new challenges for the reliable and stable operation of the connected power grid, such as intensive voltage fluctuations [3]. To mitigate those problems, the power ramp-rate $(\mathrm{RR})$ limitations are introduced to the new grid codes in many countries [4], [5]. For example,

Manuscript received September 5, 2020; revised November 8, 2020; accepted December 1, 2020. Date of publication December 30, 2020; date of current version December 15, 2020. This work was supported in part by the Research Start Fund of Nanjing Normal University under Grant 184080H202B232, in part by the National Natural Science Foundation of China under Grant 51977112, and in part by the Graduate Science and Innovation Projects in Jiangsu Province under Grant KYCX19-0808.

D. Lin, X. Li, and S. Ding are with the School of Electrical and Automation Engineering, Nanjing Normal University, Nanjing 210023, China (e-mail: xingshuo.li@njnu.edu.cn).

Y. Du is with the College of Science and Engineering, James Cook University, Australia.

Digital Object Identifier 10.24295/CPSSTPEA.2020.00027 the maximum allowable RR limitations can be defined as 10\% of the PV capacity per minute in Germany and Puerto Rico. In Denmark, the maximum power RR is $100 \mathrm{~kW} / \mathrm{s}$ [6].

In order to reduce the high variation rate of the injected power to meet the RR limitation, the power ramp rate control (PRRC) method was introduced into the PV system. Generally, the battery energy storage system (ESS) can be used for PRRC implementation by absorbing or injecting power to smooth the fluctuation [7]-[15]. The moving average (MA) [16][18] and exponential moving average (EMA) [19], [20] are most commonly used ESS methods for power smoothing applications due to its simplicity in implementation and less computational effort. However, both MA and EMA methods require a larger energy storage capacity, which leads to increased costs. Therefore, an enhanced EMA method so-called enhance linear exponential smoothing (ELES) is proposed, which is to optimize parameters set to decrease battery capacity [21], [22]. Moreover, the low-pass filter (LPF) method [23][25] and the second-order LPF (2-LPF) [26] are proposed that can serves as a reference for ESS to eliminate the higher power fluctuations.

Due to the high cost of batteries and short life expectancy, the active power curtailment (APC) method alternatively has been proposed [27]-[32]. This method is much simpler, implies lower implementation cost solution to achieve the PRRC without energy storage equipment. The basic idea of this method is the PV system working at a suboptimal power level rather than the maximum power of PV panels [33]-[36]. Therefore, a certain amount of PV power can be reserved, which will be released to smooth the output power. However, the APC method can only effectively control in the RR up control but fail to control in the RR down control [37]-[39]. Therefore, the forecasting based active power curtailment (FAPC) is proposed to predict the short-term variance rate of solar irradiance, which can successfully achieve the power control during the RR down [40], [41].

Despite the different PRRC methods proposed, there is a lack of comparison of those methods on economic performance. In addition, few researches include battery aging models to analyze the levelized cost of energy (LCOE) index, which is adopted to quantify and compare the cost for different methods [42]-[44]. The economic model generally set an ideal value of the battery life, which fail to reflect the battery aging of diverse methods [41], [42]. This paper aims to fill this gap. By comparing the LCOE of various methods, it establishes 


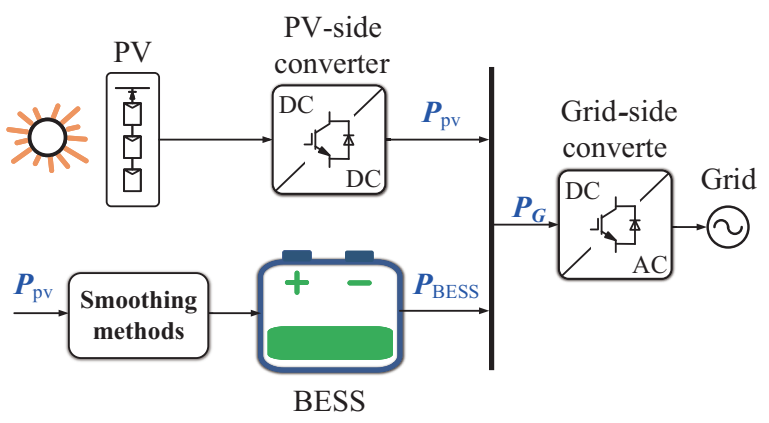

Fig. 1. The circuit layout of ESS-based PRRC method.

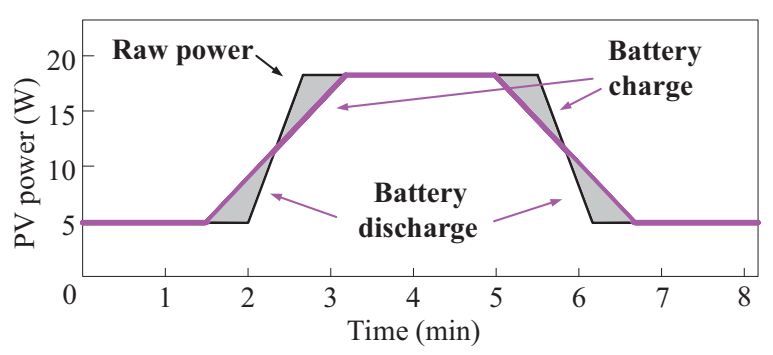

Fig. 2. The principle of ESS-based PRRC method.

which method would provide the lowest cost with considering battery aging. Furthermore, an analysis of the battery capacity requirements and the power loss of APC methods is quantified. Finally, the conclusion and suggestion by comparing different PRRC methods are summarized.

\section{ENERgy Storage System}

The general implementation of the ESS-based PRRC can be observed in Fig. 1. The layout is made up of PV module, ESS module and grid-connected DC/AC inverter. The PV module is composed of a PV array and a boost converter. The principles of the five ESS methods are shown in Fig. 2. These methods are used to smooth the high fluctuations in the PV output power. An amount of active power will be charged or discharged through the ESS to smooth fluctuations commanding by a smoothing power reference $\left(P_{\mathrm{BESS}}\right)$. Consequently, the injected grid power $\left(P_{\mathrm{G}}\right)$ can be limited within the acceptable RR.

\section{A. Moving Average}

The MA is one of the most common smoothing methods in the among ESS methods. For the control, $P_{\mathrm{BESS}}(k)$ at a given $k^{\text {th }}$ instant depends on the previous values of $P_{\mathrm{pv}}$ within the averaging window $w$. It can be expressed as:

$$
P_{\mathrm{BESS}}(k)=\frac{\sum_{i=0}^{w-1} P_{\mathrm{pv}}(k-i)}{w}-P_{\mathrm{pv}}(k)
$$

where $P_{\mathrm{pv}}(k)$ is the PV output power at the $k^{\text {th }}$ moment. The longer the window length, the better the effect of suppressing fluctuations.

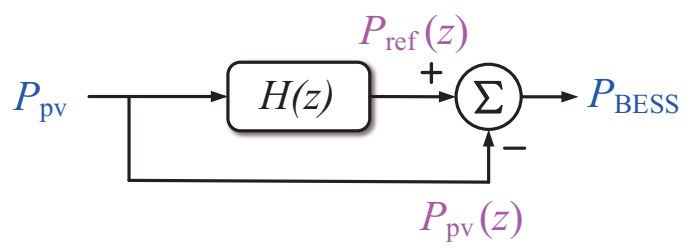

Fig. 3. Low pass filter implementation.

\section{B. Exponential Moving Average}

The EMA, similar to the MA, needs to rely on previously sampled data. However, it emphasizes on recent historical data by using the exponentially decreasing weighting terms, which can be presented as:

$$
\begin{aligned}
P_{\mathrm{BESS}}(k)= & \alpha\left[P_{\mathrm{pv}}(k)+(1-\alpha) P_{\mathrm{pv}}(k-1)+\cdots\right. \\
& \left.+(1-\alpha)^{n} P_{\mathrm{pv}}(k-n)\right]-P_{\mathrm{pv}}(k)
\end{aligned}
$$

where $n=\{0,1,2, \ldots, w-1\}$ and the factor $\alpha$ is the smoothing coefficient, which is between 0 and 1 . The weighting terms (1 $-\alpha$ ) are exponentially decreased to make the recent data more significant than the previous one.

\section{First Order Low-Pass Filter}

Low pass filter can be used to repress the high frequencies, which resides over the cutoff frequency. In the implementation of PRRC, the output power of the PV array is served as the control signal smoothed by the filter [25]. Then, the LPF method offers a power reference. The difference between the power reference and output power is compensated by charging or discharging energy from the ESS. The way to generate the power reference for the battery can be presented in Fig. 3. The discrete implementation of the LPF using Forward Euler approximation is given by:

$$
\begin{gathered}
P_{\mathrm{ref}}(z)=H(z) \cdot P_{\mathrm{pv}}(z) \\
P_{\mathrm{BESS}}(z)=H(z) \cdot P_{\mathrm{pv}}(z)-P_{\mathrm{pv}}(z) \\
H(z)=\frac{\left(T / T_{\mathrm{f}}\right) z^{-1}}{1+\left(T / T_{\mathrm{f}}-1\right) z^{-1}}
\end{gathered}
$$

where $P_{\text {ref }}$ is the expected active power of PV array smoothed by the LPF. $T$ is the sampling period and $T_{\mathrm{f}}$ represents the filter time constant. A high $T_{\mathrm{f}}$ results in better smoothing performance, while a low one will allow higher-order frequencies to pass.

\section{Second Order Low-Pass Filter}

The 2-LPF method is similar to the LPF method. The order of the filter establishes how strict the bandwidth that passes signals is, the higher the order is, the more abrupt is the reduction in the high-frequency signals, and the less of those signals are present in the filtered signals. Thus, this method 


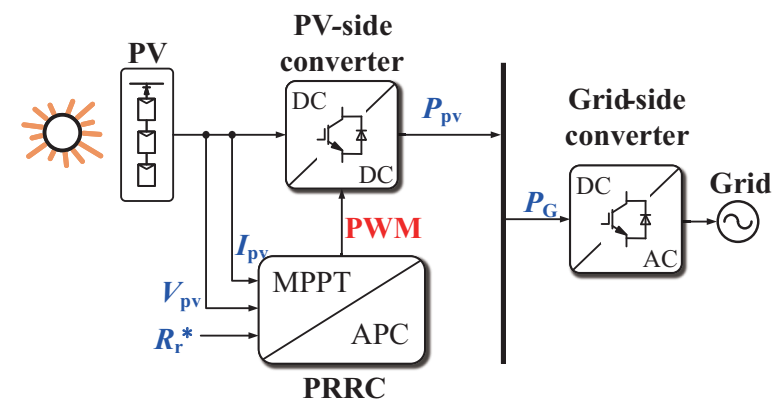

Fig. 4. The circuit layout of APC-based PRRC method.

add a steeper filtering, which can help reduce the system requirements of battery capacity. In addition, the 2-LPF method is capable of suppressing higher PV power fluctuations rather than the LPF method. The discrete implementation of the 2-LPF using Forward Euler approximation is given by:

$$
H(z)=\frac{T^{2} \omega_{\mathrm{n}}^{2} z^{-2}}{1+\left(2 \zeta \omega_{\mathrm{n}} T-2\right) z^{-1}+\left(1-2 \zeta \omega_{\mathrm{n}} T+T^{2} \omega_{\mathrm{n}}^{2}\right) z^{-2}}
$$

where $\omega_{\mathrm{n}}$ is the filter natural frequency, $\zeta$ is the damping ratio and $T$ represents the sampling period.

\section{E. Enhanced Linear Exponential Smoothing}

The ELES uses two exponential smoothed values to the smooth power fluctuation. The PV power is calculated to achieve the first exponential smoothed value, which is used to obtain the second exponential value. They are presented as:

$$
\begin{gathered}
P_{\mathrm{pv}}^{\prime}(k)=\alpha P_{\mathrm{pv}}(k)+(1-\alpha) P_{\mathrm{pv}}^{\prime}(k-1) \\
P_{\mathrm{pv}}^{\prime}(k)=\alpha P_{\mathrm{pv}}^{\prime}(k)+(1-\alpha) P_{\mathrm{pv}}^{\prime}(k-1) \\
P_{\mathrm{BESS}}(k)=2 P_{\mathrm{pv}}^{\prime}(k)-P_{\mathrm{pv}}^{\prime}(k)-P_{\mathrm{pv}}(k)
\end{gathered}
$$

where $P_{\mathrm{pv}}^{\prime}(k)$ and $P_{\mathrm{pv}}^{\prime \prime}(k)$ is the smoothed value of $k$ data points and the estimated trend of the smoothed values with $k$ data points, respectively. Additionally, smoothing coefficient $\alpha$ is between 0 and 1 .

\section{Active Power CuRtaILMent}

The APC methods is more cost-effective since it does not require ESS. In addition, as the number of potentially faulty components is reduced, the reliability of the entire system has improved. However, because there is no storage device to store the curtailed energy, the PV utilization factor is lower due to the loss of curtailed energy. In some cases, the economic losses caused by the curtailment may offset the benefits of reduced equipment costs, thus comprehensive analysis and comparison are needed.

Fig. 4 shows the circuit layout of the two APC methods. Fig. 5 presents the operational principle of the APC method. The PRRC module samples two points of the PV generated power with an interval of $60 \mathrm{~s}$. If the current RR is larger than the

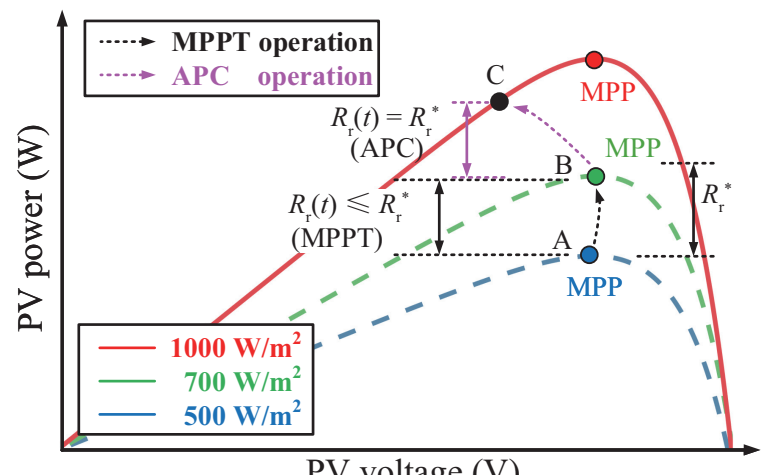

Fig. 5. Operational principle of the APC method: MPPT mode $(\mathrm{A} \rightarrow \mathrm{B})$ and APC mode $(\mathrm{B} \rightarrow \mathrm{C})$, where $R_{\mathrm{r}}(t)$ is the PV power $\mathrm{RR}$ and $R_{\mathrm{r}}^{*}$ is the RR.

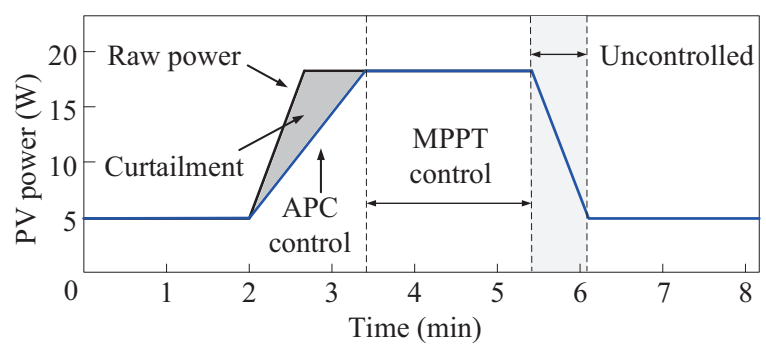

(a)

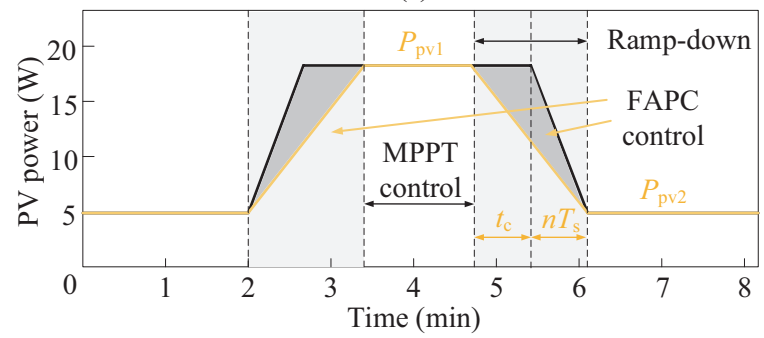

(b)

Fig. 6. The principle of APC-based PRRC method. (a) Traditional APC, and (b) forecasting-based APC.

maximum allowable RR, it will curtail the power to meet the RR limitation. Otherwise, the PV system will work at the MPP. It should be noted that the PV power is always regulated at the left side of the MPP curve. Thus, the working range of voltage is from 0 to the voltage at the MPP.

\section{A. The Traditional APC}

As shown in Figs. 5 and 6(a), if the estimated RR $R_{\mathrm{r}}(t)$ is more than the RR limit $R_{\mathrm{r}}^{*}$, the APC mode will be applied, if not, it will switch to using the MPPT mode. The above working principle can be summarized as the following formula:

$$
\begin{gathered}
V_{\mathrm{pv}}^{*}=\left\{\begin{array}{l}
V_{\mathrm{MPPT}}, \text { when } R_{\mathrm{r}}(t) \leqslant R_{\mathrm{r}}^{*} \\
V_{\mathrm{pv}}-V_{\mathrm{step}}, \text { when } R_{\mathrm{r}}(t)>R_{\mathrm{r}}^{*}
\end{array}\right. \\
R_{\mathrm{r}}(t)=\frac{P_{\mathrm{pv}}(t)-P_{\mathrm{pv}}\left(t-T_{\mathrm{S}}\right)}{T_{\mathrm{S}}}
\end{gathered}
$$



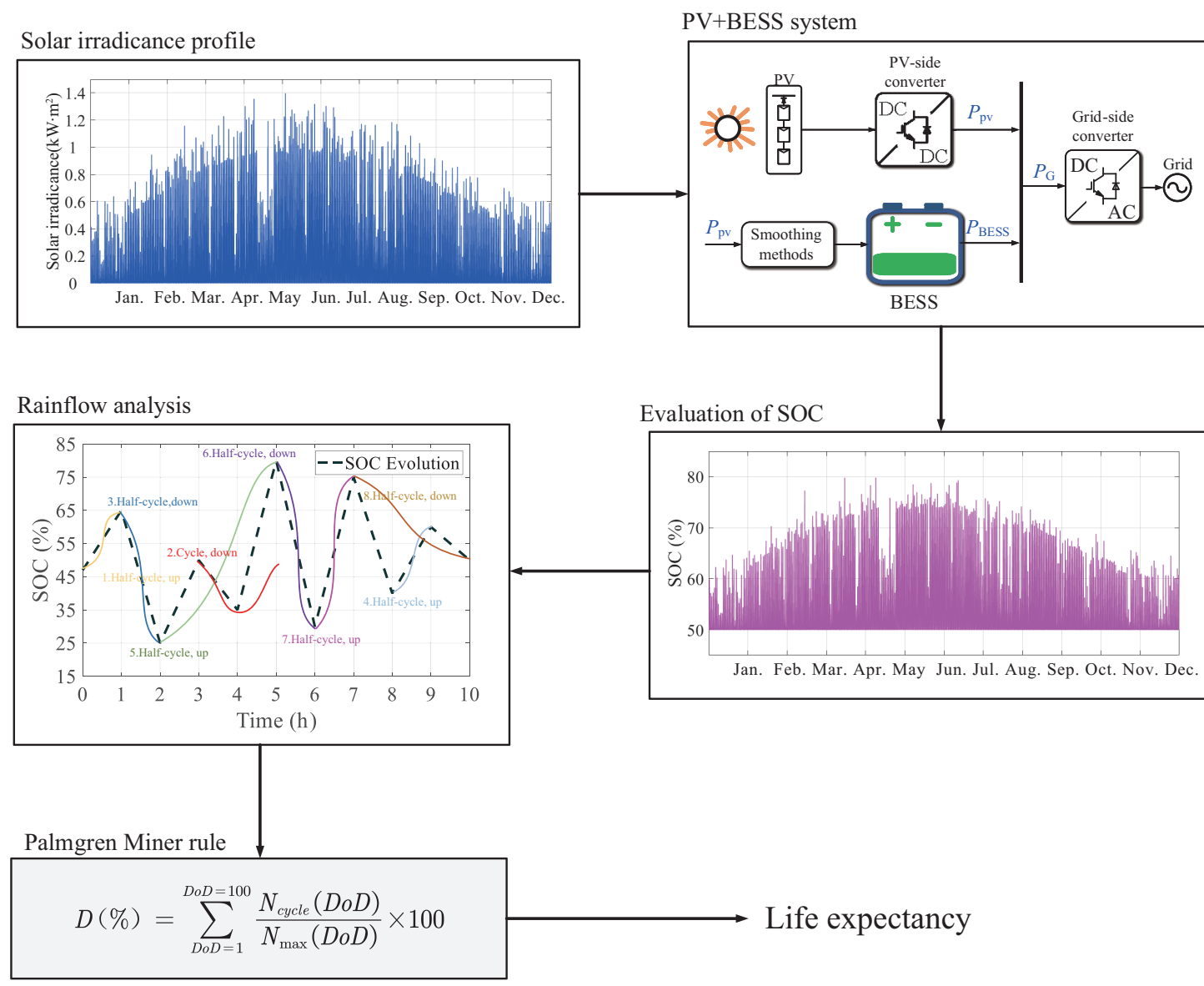

Fig. 7. The flow of the battery aging model.

where $V_{\text {step }}$ is the step size of each advance. There are many ways to calculate $R_{\mathrm{r}}(t)$. This paper chooses a fixed duration $\left(T_{\mathrm{S}}\right.$ $=60 \mathrm{~s})$ for calculation.

However, the traditional APC does not work under the rampdown events. Because there is no extra power to prevent RR from falling too fast.

\section{B. Forecasting Based APC}

To address power curtailment in ramp-down fluctuation, the FAPC method was introduced, whose performance is shown in Fig. 6(b).

The FAPC can effectively predict the arrival time of cloud shadows by using the ground-based sensor forecasting system (GBSFS). Thus, the FAPC method can curtail the power before the solar irradiance sharply decreasing. In this method, $P_{\mathrm{pv} 1}$ and $P_{\mathrm{pv} 2}$ denote the power of PV at the beginning of falling time and the power during cloud shadow, respectively. $R_{\mathrm{s}}$ is the uncontrolled RR and $R_{\mathrm{r}}^{*}$ is the controlled RR. If $R_{\mathrm{s}}$ exceeds RR limitation, it can increase $t_{\mathrm{c}}$ to led that $R_{\mathrm{r}}^{*}$ conforms to RR limitation. It can be expressed as:

$$
\begin{aligned}
& R_{\mathrm{s}}=\frac{P_{\mathrm{pv} 1}-P_{\mathrm{pv} 2}}{n T_{\mathrm{S}}} \\
& R_{\mathrm{r}}^{*}=\frac{P_{\mathrm{pv} 1}-P_{\mathrm{pv} 2}}{t_{\mathrm{c}}+n T_{\mathrm{S}}}
\end{aligned}
$$

where $t_{\mathrm{c}}$ is the time for PV to reduce power in advance, falling time of power $\left(n T_{\mathrm{S}}\right), T_{\mathrm{S}}$ is GBSFS sampling time period.

\section{ECONOMIC ANALYSIS}

\section{A. Battery Aging Model}

This battery aging model is combined with the rain flowcounting (RFC) algorithm [45]-[47] and Palmgren-Miner rule [48]-[51]. In this way, the hybrid method provides an estimation of the expected life of the battery under PRRC [52].

Fig. 7 shows the flow of the battery aging model. Through the combination system of PV and BESS, we use a year data collected by the Humboldt State University to estimate the state of charge (SOC) curve. Then, the SOC curve is put into Rainflow analysis to evaluate the cycle situation of battery. Finally, the cumulative number of cycles are brought into the Palmgren-Miner rule to establish the life expectancy.

For the Palmgren-Miner rule, the cumulative number of cycles divided by the maximum number of cycles at each the depth-ofdischarge (DoD) level. Then, it add up the 100 ratios to estimate the degree of battery degradation. The formula is as follows:

$$
D(\%)=\sum_{D_{\mathrm{o}} D=1}^{D_{\mathrm{o}} D=100} \frac{N_{\text {cycle }}\left(D_{\mathrm{o}} D\right)}{N_{\max }\left(D_{\mathrm{o}} D\right)} \times 100
$$


where $D(\%)$ represents the degree of battery degradation, $N_{\text {cycle }}$ is the cumulative number of cycles under different degrees of DoD. $N_{\max }$ denote the maximum number of cycles that the battery can endure for each specific DoD, according to the capacity evolution curve provided by the manufacturer. For example, the capacity evolution curve of the Intensium Max High Power VL30P battery type of SAFT battery can be approximated by the following equation:

$$
N_{\max }(D o D)=3 \times 10^{-7} \times D o D(\%)^{-1.825}
$$

Then, the degree of battery degradation $D(\%)$ can estimate the battery reference cycle $(N C)$ number. From (13), the batteries can endure around 10000 cycles at $80 \%$ DoD, thus the $N C$ can be calculated as:

$$
N C(@ 80 \%)=\frac{D(\%) \times 10000}{100 \%}
$$

Finally, considering the reference working temperature (T) as $25^{\circ} \mathrm{C}$, the $N C$ and $T$ should be brought into the semiempirical mathematical model [53], which considers the impact of calendar and cycle aging on the capacity attenuation of batteries. The equations are as follows:

$$
\begin{gathered}
C_{\text {fade_calendar }}(t, T)=a_{t} \times e^{\beta_{t} \cdot T} \times t^{n} \\
C_{\text {fade_cycle }}(N C, T)=a_{N C} \times e^{\beta_{N C} \cdot T} \times N C^{n} \\
R C=1-\left[C_{\text {fade_calendar }}\left(y_{\mathrm{EOL}}, T\right)+C_{\text {fade_cycler }}(N C, T) \times y_{\text {EOL }}\right]
\end{gathered}
$$

where the retained capacity $(R C)$ is the ratio of the remaining capacity of the battery to the initial capacity expressed as a percentage. It is generally believed that the battery should be scrapped when $R C=70 \%$. The end-of-life (EOL) is expressed in years $\left(y_{\mathrm{EOL}}\right)$ and in months $(t)$, which can be used as the estimated life expectancy of the battery under the corresponding PRRC. The correlation coefficient in the formula is as follows: $a_{t}=3.087 \cdot 10^{-7}, a_{N C}=6.87 \cdot 10^{-5}, \beta_{t}=$ $0.05146, \beta_{N C}=0.027$ and $n=0.5$.

\section{B. The Levelized Cost of Energy}

Different ESS methods may require the battery to operate at different regimes, which directly relates to the requirement of battery capacity and battery lifetime. Another solution, APC methods lead to power loss, which obviously raises the total cost. Thus, the economic loss of APC comes from loss of power, while the extra cost of ESS is affected by battery cost. To compare the economic cost, the mathematical model of the LCOE is applied. This model divides all the costs of the equipment by the energy generated during its life expectancy. The formula is as follows:

$$
\operatorname{LCOE}(\$ / \mathrm{kWh})=\frac{\sum_{y=1}^{n} \frac{I_{y}+O_{y}+F_{y}}{(1+d)^{y}}}{\sum_{y=1}^{n} \frac{E_{y}}{(1+d)^{y}}}
$$

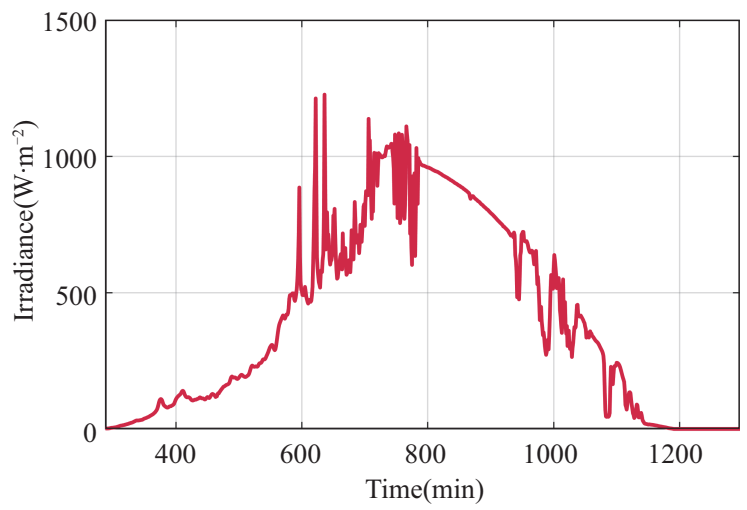

Fig. 8. Solar irradiance data collected by Humboldt State University, 2018 June 21.

where $I_{y}$ is the initial installation cost, $O_{y}$ is the annual maintenance cost, and $F_{y}$ is the fuel cost. $E_{y}$ is the power emitted by the PV system each year, and $n$ is the battery life obtained from the battery aging model in years. The cost and energy obtained each year are affected by the discount rate $d$. The values are set as follows:

- $I_{y}$ - The cost of the PV plant, battery, and forecasting system only is calculated in the first year $(y=1)$, that is. The cost of PV plant is directly proportional to the peak cost. There is no need to consider battery investment costs in the APC control strategy.

- $O_{y}$-Annual operation and maintenance costs generally use $3.5 \%$ of the initial investment cost [42].

- $F_{y}$-Fuel cost is zero for the PV example.

- $d$-Discount rate $d$ is $4 \%$.

- $E_{y}$-Need to consider the power loss caused by the APC algorithm.

\section{Simulation Results}

\section{A. Simulation Setup}

i) Data: A full year of solar irradiance data is used to evaluate the performance of PRRC methods. The data from 1st of January, 2018 to 31th of December, 2018 is collected by National Renewable Energy Lab (NREL) in Humboldt State University, California (coastal area), and its temporal resolution is one minute [54]. All the solar irradiance data has been used for simulation. However, it is difficult to present the full year of solar irradiance data in one figure. Therefore, the data of 21th of June is just selected as a demo to demonstrate the smooth performance of different PRRCs. It can be clearly seen that the selected day is a typical day. It has drastic fluctuations, small fluctuations, and no fluctuation, as shown in Fig. 8 [54].

The operating temperature is set as $25^{\circ} \mathrm{C}$ in this work. In the day, solar irradiance could be dramatically changed, but the temperature does not. Furthermore, the temperature does not have much effect on power [55], [56]. In addition, temperature significantly affects battery aging. Therefore, for extending the lifetime, the operating temperature of the battery cells should be kept under control and as close as possible to the $20-25^{\circ} \mathrm{C}$ 
TABLE I

Main Product Parameters of the PV Module MSX-60W

\begin{tabular}{lcc}
\hline \hline Parameter & Symbol & Value \\
\hline Maximum power & $P_{\mathrm{mpp}}$ & $60 \mathrm{~W}$ \\
Voltage at maximum power & $V_{\mathrm{mpp}}$ & $17.1 \mathrm{~V}$ \\
Current at maximum power & $I_{\mathrm{mpp}}$ & $3.5 \mathrm{~A}$ \\
Open-circuit voltage & $V_{\mathrm{oc}}$ & $21.1 \mathrm{~V}$ \\
Short-circuit current & $I_{\mathrm{sc}}$ & $3.8 \mathrm{~A}$ \\
Temperature coefficient of $V_{\mathrm{oc}}$ & $K_{v}$ & $-80 \mathrm{mV} /{ }^{\circ} \mathrm{C}$ \\
Temperature coefficient of $I_{\mathrm{sc}}$ & $K_{i}$ & $0.065 \% /{ }^{\circ} \mathrm{C}$ \\
\hline \hline
\end{tabular}

recommended by manufacturers [52].

ii) System description: Simulation model has been built using Matlab/Simulink software. The specifications of PV module are shown in Table I. For all the PRRC methods under test, the battery was assumed to be the same size. The rated capacity of the battery is $50 \mathrm{Wh}$, and the maximum charge and discharge power is $45 \mathrm{~W}$.

iii) RR calculation: There are many ways to calculate RR, and different countries choose different calculation methods. In this paper, the RR calculation is considered as the power difference between the two endpoints of a given 60 -second interval. The calculation method is as follows:

$$
R R(t)=\frac{P(t)-P(t-60)}{60}
$$

where $P(t)$ is the grid power and $P(t-60)$ represents the grid power interval 60 seconds ago. In addition, the RR limit of the $\mathrm{PV}$ plant rated power is set to $10 \%$ per minute.

\section{B. ESS}

i) MA: In Fig. 9, the MA smoothing strategy's simulation results for a 5-minutes to a 20-minutes window length are shown. As the window length increases, the smoothing performance of power fluctuation is better, as shown in Fig. 9(a). The reduction in the power fluctuation is more obviously shown in Fig. 9(b), where a quantification of the RR in \%/minute is represented. For a window length longer or equal to 10-minutes, the methods could maintain the RR below $10 \%$ per minute in the day.

Fig. 9(c) shows the increase in SOC variation as the MA window increases, which comes from the fact that more power is needed to absorb as the result of more strictly limiting power fluctuations. However, to absorb more active power, battery capacity is more large, leading to an increase in the cost. This method can guarantee that the initial SOC and the final SOC are at an identical level, which the basic requirement for longterm operation.

ii) EMA: In Fig. 10, the investigation of the EMA smoothing approach for a considered window length of 20-minutes and a smoothing factor $\alpha$ from 0.3 to 0.15 is demonstrated. As can be observed in Fig. 10(a) and (b), the reduction in smoothing

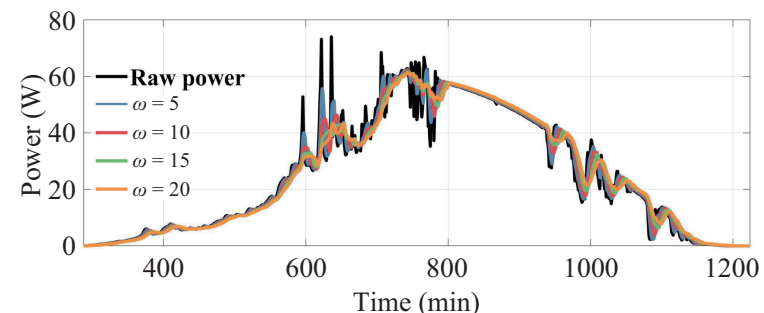

(a)

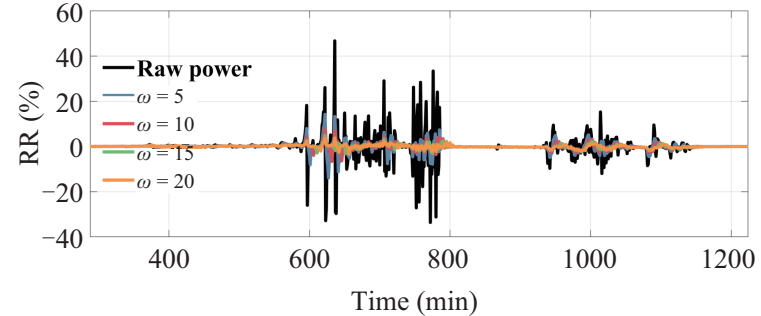

(b)

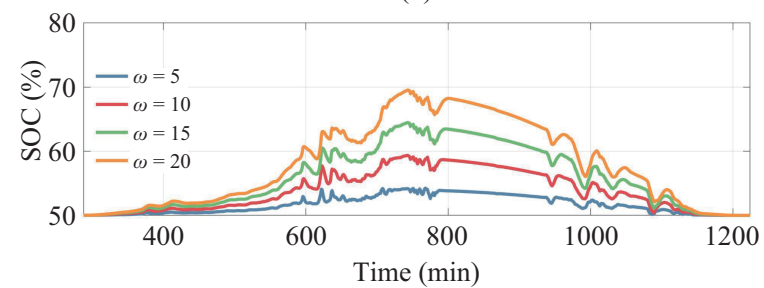

(c)

Fig. 9. PV+BESS system with the applied MA smoothing technique for a 5-minute to 20-minute window. (a) Output power. (b) RR in \% per minute. (c) SOC.

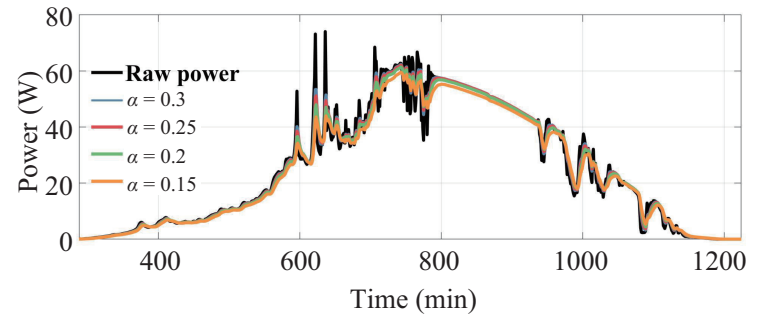

(a)

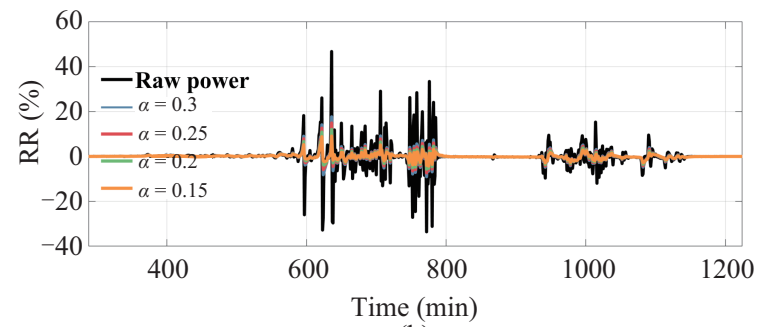

(b)

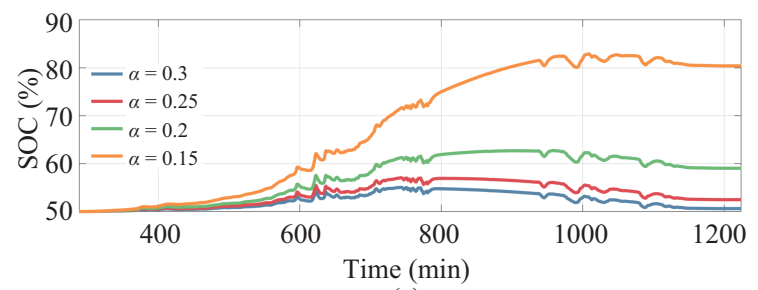

(c)

Fig. 10. PV+BESS system for 20-minute of applied EMA smoothing technique with $\alpha=0.3$ to 0.15 . (a) Output power. (b) RR in $\%$ per minute. (c) SOC. 


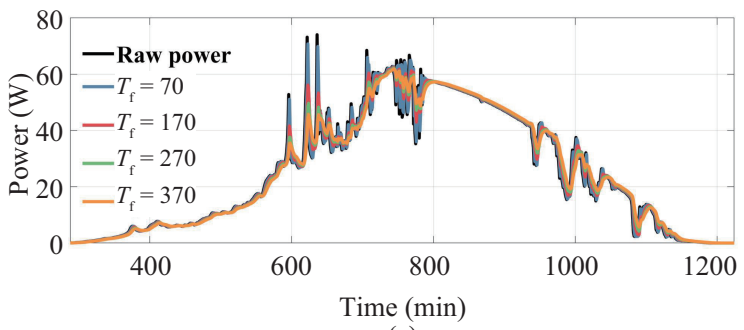

(a)

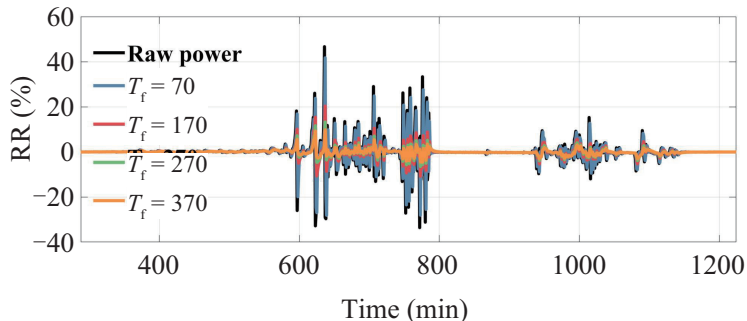

(b)

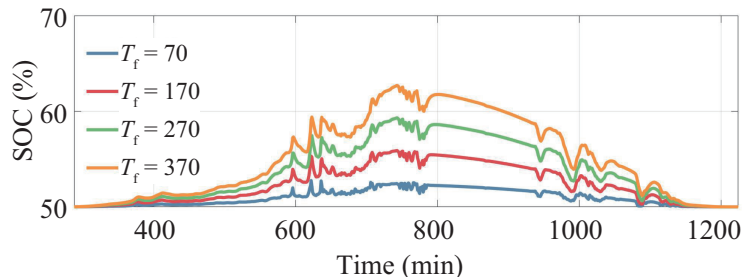

(c)

Fig. 11. PV+BESS system for 70 seconds to 370 seconds of applied LPF smoothing technique: (a) Output power. (b) RR in \% per minute. (c) SOC.

factor $\alpha$ can achieve a more strict limit of RR. In addition, for a $\alpha$ value below or equal to 0.15 , the EMA method is proved to have the ability to achieve the RR below $10 \%$ /minute of the rated power. For suitable the long-term operation of the battery, and the SOC level needs to be corrected back to $50 \%$ at the end of each day. As can be seen from Fig. 10(c), the EMA requires a larger capacity than that of the MA to achieve the limit of RR in $10 \%$ /minute. The ESS is excessively charged to over smooth the ramp rate, leading to the failure to regain the $50 \% \mathrm{SOC}$ at the end. This indicates that a great percentage of the system's generated power is not injected into the grid but storage. In addition, if stored power cannot restore to $50 \%$ SOC, the daily accumulated power will pass over the battery capacity. It will lead that the ESS fails to smooth the output power through charging power.

iii) First Order LPF: In Fig. 11 the impact of the LPF smoothing method for different filter time constant was presented. The increase in the filter time constant from 70 -seconds to 370 -seconds has diminished fluctuations in power injected into the grid. From Fig. 11(a) and (b) the maximum value of $\mathrm{RR}$ from about $41.8 \%$ /minute at 70 -seconds to $9.8 \%$ at 370 -seconds is reduced by increasing the filter time constant. Moreover the SOC level can be restored to the initial position at the beginning of the day. For the limitation of RR in $10 \% /$ minute, the required capacity of LFP is smaller than the EMA method but larger than the MA method.

iv) 2-LPF: The research of the 2-LPF smoothing method for different natural frequencies and considering a constant

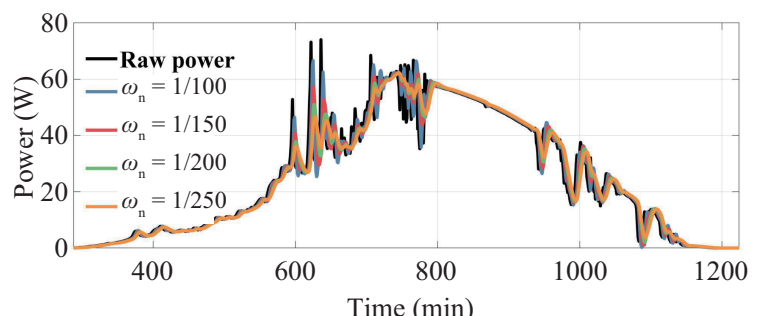

(a)

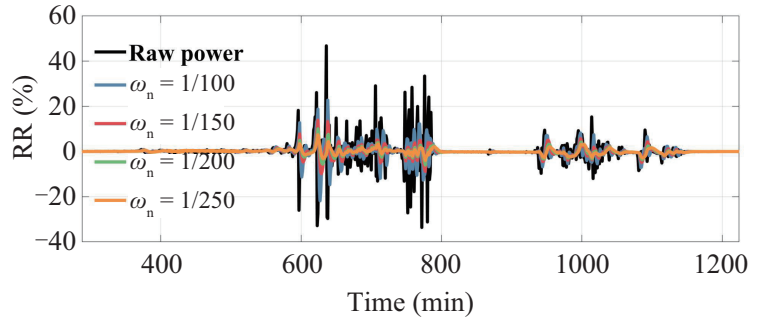

(b)

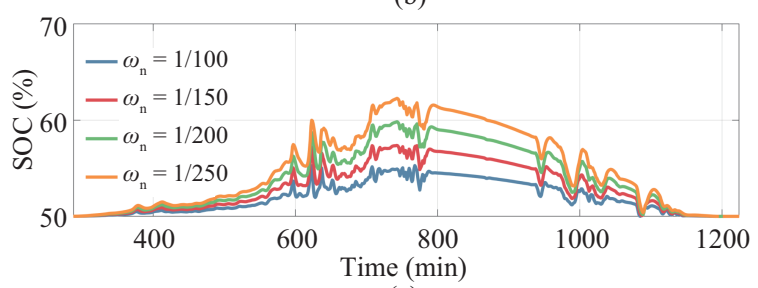

(c)

Fig. 12. PV+BESS system for $1 / 100 \mathrm{rad} / \mathrm{s}$ to $1 / 250 \mathrm{rad} / \mathrm{s}$ of applied 2-LPF smoothing technique. (a) Output power. (b) RR in \% per minute. (c) SOC.

damping factor of 0.707 is provided in Fig. 12. It can be observed from Fig. 12(a) and (b) that as the natural frequencies increase, the power fluctuations injected into the grid are reduced. For an $\omega_{\mathrm{n}}$ of $1 / 100 \mathrm{rad} / \mathrm{s}$ to $1 / 250 \mathrm{rad} / \mathrm{s}$, the system decreases the maximum value of RR from $22.7 \%$ /minute to $7.5 \% /$ minute. It can be seen from Fig. 12(c) that the SOC variance of 2-LPF is different to the MA and EMA methods. At the end of each day, the SOC level is also returned to $50 \%$. In addition, the required capacity of this method is larger than MA under the limitation of $R R=10 \%$. A drawback of LPF and 2-LPF is that during a clear sky day, with little variation in irradiance, the method still offers a power reference, which leads to the battery operation even when it is not needed.

v) ELES: In Fig. 13, the study of the ELES smoothing strategy for different smooth factors $\alpha$ is shown. The ELES method is an improved method from the EMA method, retaining the smoothing factor. As shown in Fig. 13(a) and (b), the decrease in smoothing factor reduces the amplitude of the power fluctuations. For a smoothing factor smaller or equal to 0.08 , the method proofs sufficient in keeping the RR below 10\%/minute of the rated power. Compared with the EMA method, the ELES method can restore the SOC level to $50 \%$ at the end of the day. Although this method requires the smallest battery capacity to meet $R R=10 \%$, the required battery capacity increases dramatically at the smoothing factor equal to 0.04 .

\section{Comparison of Different ESS Methods Under RR $=10 \%$ Limitation}

In order to proper compare the different ESS-based PRRC 


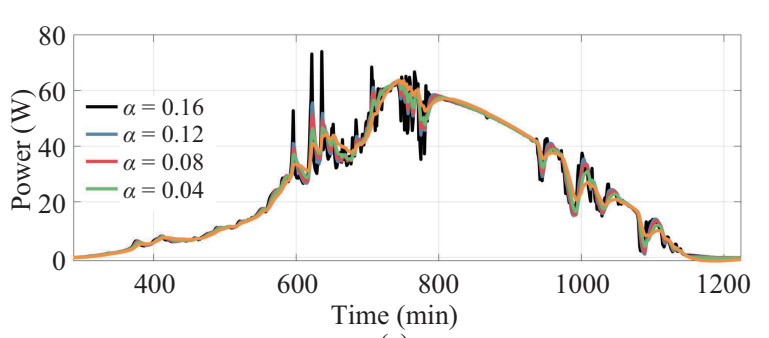

(a)

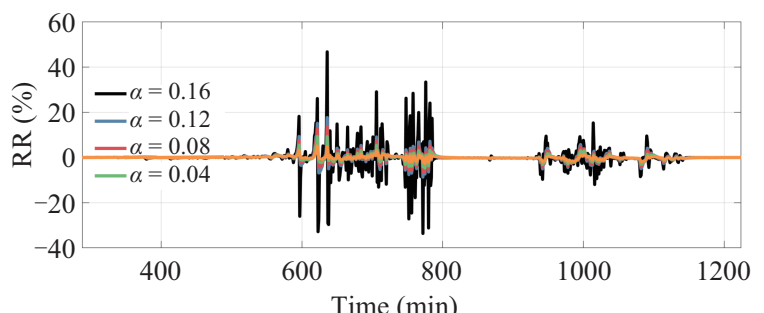

(b)

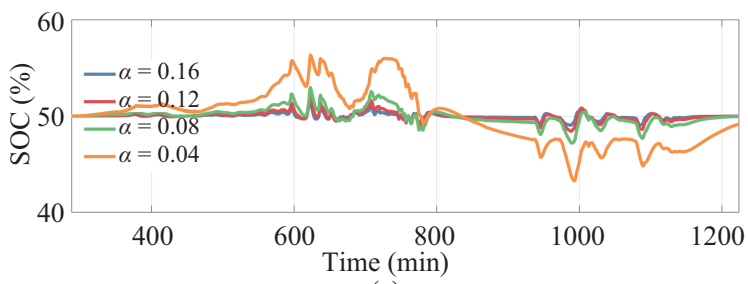

(c)

Fig. 13. PV+BESS system applied ELES smoothing tech-nique with $\alpha=0.16$ to 0.04. (a) Output power. (b) RR in \% per minute. (c) SOC.

methods, the following practical features were considered:

- The limitation of RR is $10 \%$ per minute of the rated power.

- Battery SOC level and status at end of the day.

- Battery capacity.

In order to achieve the limit RR to $10 \%$ per minute, the parameters of different PRRCs be carefully tuned by using the trial-and-error method [6], [21]. The parameters are set as follow: the window length of the MA method is 10 , the smoothing coefficient of the EMA method is 0.15 , the filter time constant of the LPF method is 370 , the natural frequency of the 2-LPF method is $1 / 200$, and the smoothing coefficient of the ELES method is 0.08 .

As shown in Fig. 14(a) and (b), different ESS methods represent similar smooth performance in the power fluctuation. However, the EMA method requires the largest battery capacity and cannot reset the SOC to $50 \%$ at the end, as presented in Fig. 14(c). The ELES method requires the smallest battery capacity to achieve the limit RR to $10 \%$ per minute.

To further compare the requirement of capacity under different PRRC methods, the annual SOC variations are depicted in Fig. 15. The ESS is unnecessarily operated under the LPF and 2-LPF methods, which results in high SOC variation level. In addition, if a $20 \mathrm{Wh}$ battery is used, the wrong operation of the MA method will lead to a higher SOC variation level than the ELES method. However, if a larger capacity battery is used, such as $50 \mathrm{Wh}$, the SOC variation level difference between the two methods is smaller. Besides, the ELES method is the only method that controls the ESS to below 50\% SOC. If using the

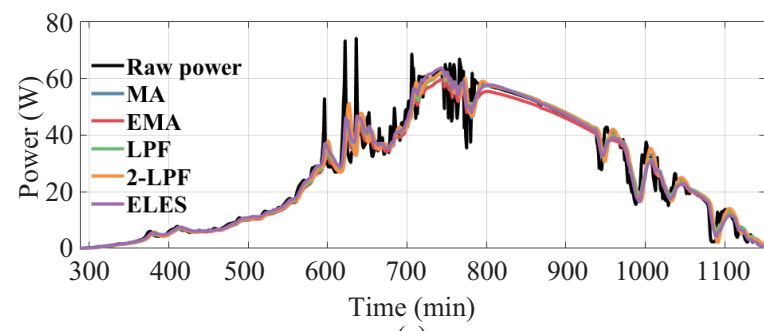

(a)

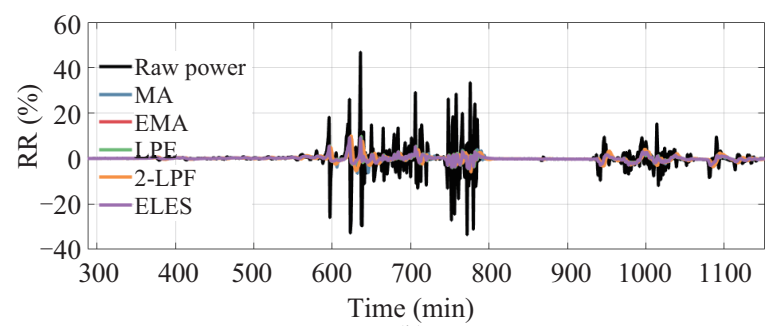

(b)

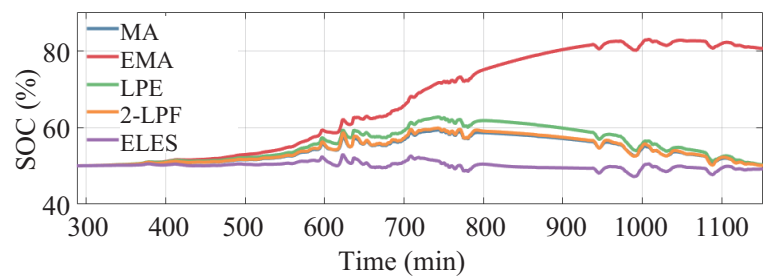

(c)

Fig. 14. PV+BESS system applied five smoothing techniques of ESS with limitation $R R=10 \%$. (a) Output power. (b) RR in \% per minute. (c) SOC.

MA method, the initial SOC can set a smaller value that can reduce the requirement of battery capacity.

\section{D. $A P C$}

i) The traditional APC: As shown in Figs. 16 and 17, the consequent of the APC smoothing technique for different $\mathrm{RR}$ limitation is presented. Unlike the above five ESS-based PRRC methods, the APC method does not require the ESS. In the case of power in the up-rate, the traditional APC method can effectively smooth power fluctuations. However, due to without predicting the power in the down-rate situation, it fails to curtail the power to meet the RR limitation effectively. It can be seen from Fig. 17(a) that large power fluctuations often occur within a short period of time, thus the loss power accounts for a small proportion of the overall output power.

ii) FAPC: In Figs. 16 and 17, the investigation of the FAPC smoothing strategy for different RR limitation is displayed. Based on the GBSFS device can provide prediction information without considering error, the FAPC method can effectively achieve the RR limit of the power in the downrate situation. The FAPC method curtails more power than the traditional APC method, but the additional curtailment power is a small part.

\section{E. Economic Analysis Results}

i) Battery aging analysis results: Since the SOC of the EMA method cannot return to $50 \%$ at the end of the day, it has been 


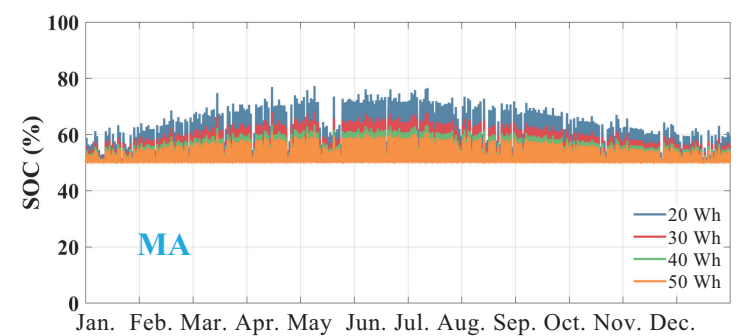

(a)

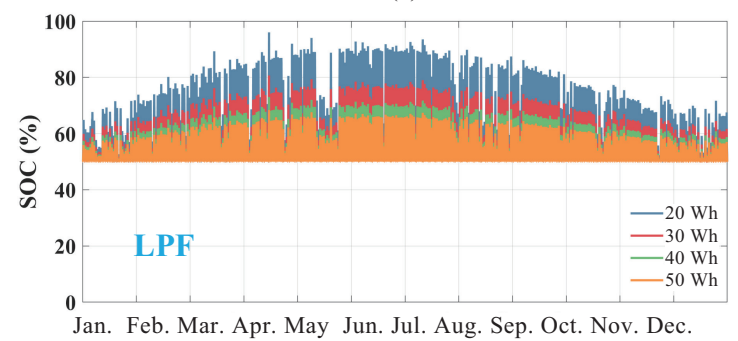

(b)

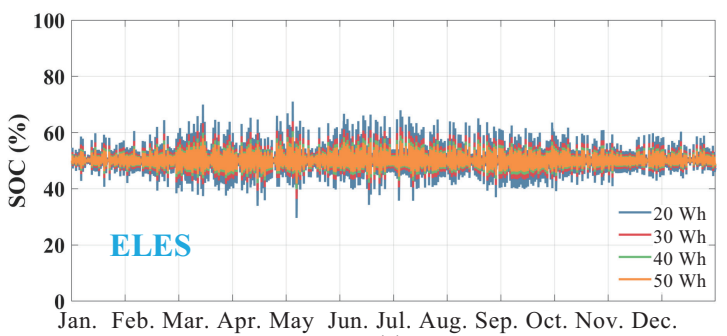

(c)

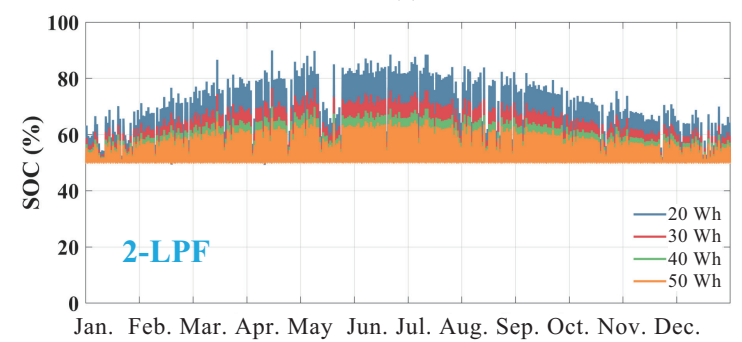

(d)

Fig. 15. Annual SOC curve of 4 ESS methods by using 4 different battery capacities, respectively. (a) MA method, (b) ELES method, (c) LPF method and (d) 2-LPF method.

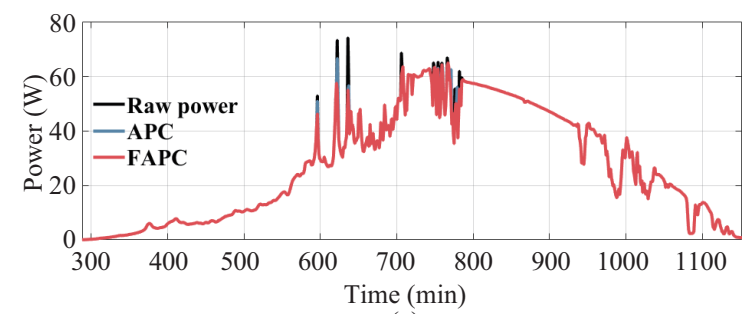

(a)

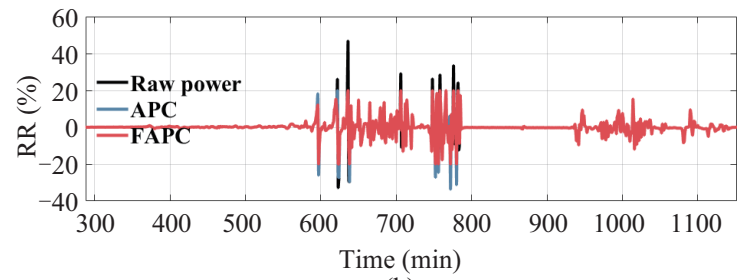

(b)

Fig. 16. PV system applied APC and FAPC smoothing techniques with $R R=20 \%$, respectively. (a) Output power and (b) RR in \% per minute.

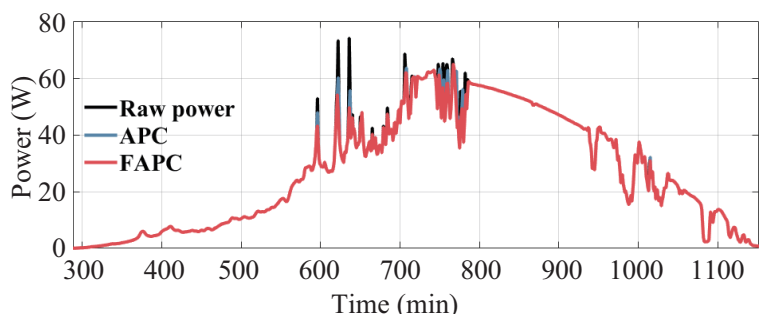

(a)

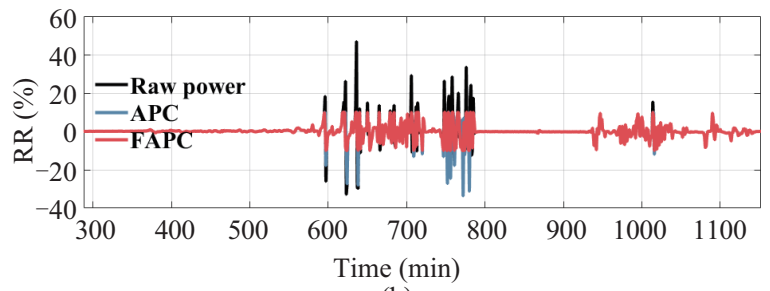

(b)

Fig. 17. PV system applied APC and FAPC smoothing techniques with RR = $10 \%$, respectively. (a) Output power and (b) RR in \% per minute.

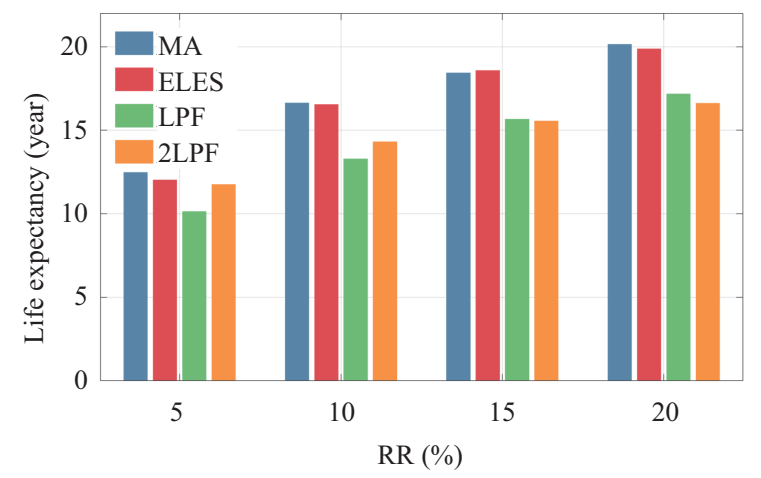

Fig. 18. Comparison of life expectancy of 4 ESS methods under different RR conditions by using $50 \mathrm{Wh}$ battery capacity.

left out the following discussion. As shown in Fig. 18, different ESS methods are compared under achieving different limits of RR. The MA and ELES methods' life expectancy is similar and longer than LPF and 2-LPF methods. It should be noted that the 2-LPF method is not always better than the LPF method. When the limit of RR is less strict, the lifetime of LPF is longer than that of 2-LPF. If the restriction is more relaxed, the life expectancy of the battery will be longer. It should be pointed out that most countries and locations need the PV station to meet the limit of RR in $10 \%$ /minute. For the limit of RR in $10 \%$ per minute, previous works set the battery's estimated life to 2 years [40] or ten years [42]. However, the life expectancy estimation in this work using the battery aging model is closer to the real situation.

As seen in Fig. 19, the life expectancy of various methods is demonstrated under using different capacities to achieve the limit of RR in $10 \%$ per minute. As the rise capacity, the lifetime is longer. Although using $50 \mathrm{Wh}$ can extend battery life by about 5 years than using $20 \mathrm{Wh}$, the cost of using $50 \mathrm{Wh}$ is 1.5 times that of using $20 \mathrm{Wh}$. Thus, the longer life expectancy does not mean more cost-effective. 


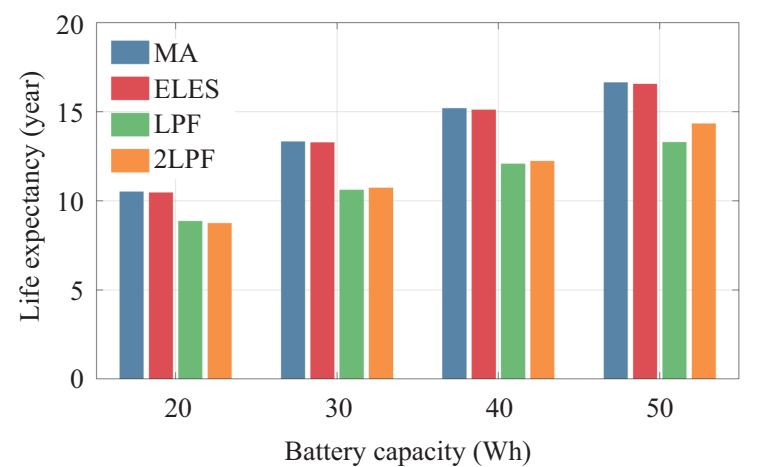

Fig. 19. Comparison of life expectancy of 4 ESS methods on the RR of $10 \%$ per minute under different battery capacity.

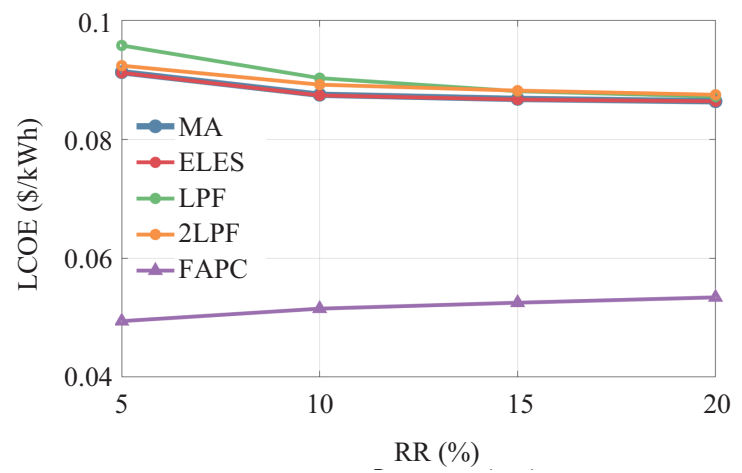

Fig. 20. The LCOE comparison of 5 PRRCs with RR in $5 \%$ to $20 \%$ per minute.

ii) LCOE analysis results: The installed cost of PV is about $650 \$ / \mathrm{kWh}$. Assuming that the PV panel is expected to be 20 years, the installed cost of the PV panel will be shared in these 20 years. And the installed cost of the battery is $500 \$ / \mathrm{kWh}$. Through the above ESS comparative analysis, it can be seen that the required capacity of the ELES method is the smallest among the five ESS methods, and the life expectancy of the MA and ELES methods is longer. For the FAPC method, the cost of a GBSFS is estimated at 145 USD. If 20 GBSFSs are applied to surround the 1.5 MW PV system, an expense of 3000 USD can be enough to build the GBSFS system. If the additional cost, such as maintenance, is considered, the GBSFS system cost is $0.05 \mathrm{USD} / \mathrm{W}$ [40]. Therefore, $0.05 \mathrm{USD} / \mathrm{W}$ is added to the LCOE calculation for the FAPC. Since the APC method cannot be controlled under the ramp-down event, the MA, ELES, and FAPC methods are main selected for discussion and comparison of the total cost.

As shown in Fig. 20, the LCOE of five smoothing strategies is presented in the different RR limitations. The LCOE of ESS methods will increase as the maximum value of RR decreases. Especially, the LPF and 2-LPF methods are particularly obvious. When the RR is from $5 \%$ to $20 \%$, the LCOE of the ESS methods is higher than that of the FAPC method. It reflects that additional energy storage devices' cost is greater than the energy losses cost. Despite prediction errors, the cost of the FAPC is still better. It should be noted that the LCOE of FAPC methods increases as the less strict restrictions of RR.

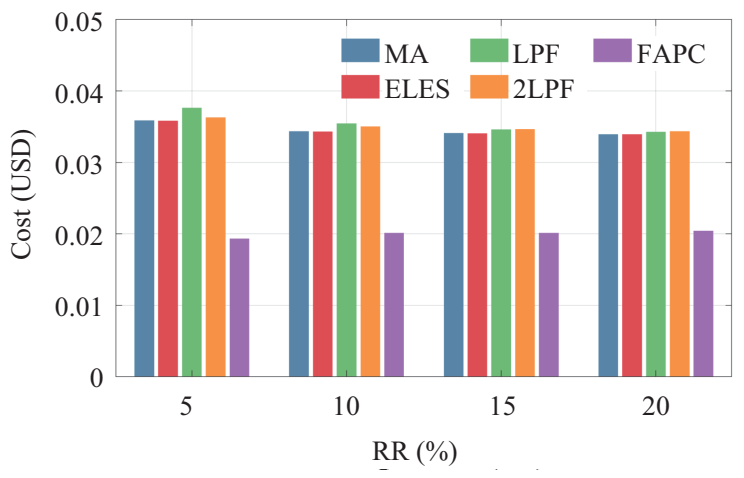

Fig. 21. The cost comparison of 5 PRRCs with RR in $5 \%$ to $20 \%$ per minute on June 21, 2018.

TABLE II

Summarization on the PRRC Methode Based on RR of 10\%/MIN

\begin{tabular}{lcccc}
\hline \hline Method & Ref. & $\begin{array}{c}\text { Required } \\
\text { capacity }\end{array}$ & $\begin{array}{c}\text { SOC at the } \\
\text { end of day } / \%\end{array}$ & $\begin{array}{c}\text { Life } \\
\text { expectancy }\end{array}$ \\
\hline MA & {$[16]-[18]$} & Moderate & 50 & 16.63 \\
EMA & {$[19],[20]$} & Large & 80 & - \\
ELES & {$[21],[22]$} & Small & 50 & 16.54 \\
LPF & {$[23],[24]$} & Large & 50 & 13.27 \\
2-LPF & {$[26]$} & Moderate & 50 & 14.31 \\
APC & {$[27]-[32]$} & - & - & - \\
FAPC & {$[40],[41]$} & - & - & - \\
\hline \hline Method & Ramp up & Ramp down & Efficiency/\% & LCOE \\
\hline MA & Control & Control & 100 & 0.0875 \\
EMA & Control & Control & 100 & - \\
ELES & Control & Control & 100 & 0.0874 \\
LPF & Control & Control & 100 & 0.0903 \\
2-LPF & Control & Control & 100 & 0.0892 \\
APC & Control & Uncontrol & 99.13 & 0.0512 \\
FAPC & Control & Control & 98.59 & 0.0522 \\
\hline \hline
\end{tabular}

Fig. 21 shows the ESS methods and FAPC method's total cost under the above solar radiation profile, June 21. Even if to achieve more strict restrictions, the cost variation of the FAPC method is relatively small, reflecting that the curtailed power accounts for a small percentage of the power generated PV by using the method. Also, to meet RR of $10 \%$ per minute, the ELES and MA method cost 0.0874 USD and 0.0875 USD, respectively, while the FAPC method costs 0.0512 USD. Therefore, the FAPC method is a more cost-effective solution rather than ESS methods.

Finally, the performance of the different PRRCs is summarized in Table II under the RR of $10 \% / \mathrm{min}$.

\section{CONCLUSION}

The smooth performance of 5 different ESS-based and 2 
different APC-based PRRC methods and is compared, which present that the battery life-expectancy of the MA and ELES methods is longer than other methods by using the aging model. Besides, the power loss of the FAPC method is small, which efficiency could reach to $98.59 \%$ for RR of $10 \% / \mathrm{min}$ without considering the forecasting error. Since the power loss accounts for a small proportion of the total generated power, the LCOE of FAPC does not change much in the RR range from $20 \% / \mathrm{min}$ to $5 \% / \mathrm{min}$. In addition, the LCOE of MA and ELES is about two times that of FAPC for RR of $10 \% / \mathrm{min}$. Although MA and ELES methods can reduce the battery's cost by using smaller capacity, the FAPC method is more cost-effective due to the small power loss.

\section{REFERENCES}

[1] Y. Wang, V. Silva, and M. Lopez-Botet-Zulueta, "Impact of high penetration of variable renewable generationon frequency dynamics in the continental Europe interconnected system," in IET Renewable Power Generation, vol. 10, no. 1, pp. 10-16, Jan. 2016.

[2] P. G. Bueno, J. C. Hernández, and F. J. Ruiz-Rodriguez, "Stability assessment for transmission systems with large utility-scale photovoltaic units," in IET Renewable Power Generation, vol. 10, no. 5, pp. 584-597, May 2016

[3] A. Woyte, V. Van Thong, R. Belmans, and J. Nijs, "Voltage fluctuations on distribution level introduced by photovoltaic systems," in IEEE Transactions on Energy Conversion, vol. 21, no. 1, pp. 202-209, Mar. 2006.

[4] B. Crăciun, T. Kerekes, D. Séra, R. Teodorescu, and U. D. Annakkage, "Power ramp limitation capabilities of large PV power plants with active power reserves," in IEEE Transactions on Sustainable Energy, vol. 8, no. 2, pp. 573-581, Apr. 2017.

[5] M. Saleh, L. Meek, M. A. S. Masoum, and M. Abshar, "Battery-less short-term smoothing of photovoltaicgeneration using sky camera," in IEEE Transactions on Industrial Informatics, vol. 14, no. 2, pp. 403-414, Feb. 2018.

[6] J. Martins, S. Spataru, D. Sera, D.-I. Stroe, and A. Lashab, "Comparative study of ramp-rate control algorithms for PV with energy storage systems," in Energies, vol. 12, no. 7, p. 1342, 2019.

[7] J. Chen, J. Li, Y. Zhang, G. Bao, X. Ge, and P. Li, "A hierarchical optimal operation strategy of hybrid energy storage system in distribution networks with high photovoltaic penetration," in Energies, vol. 11, no. 2, p. 389, 2018.

[8] M. Datta and T. Senjyu, "Fuzzy control of distributed PV inverters/energy storage systems/electric vehicles for frequency regulation in a large power system," in IEEE Transactions on Smart Grid, vol. 4, no. 1, pp. 479-488, Mar. 2013.

[9] M. Khooban, T. Dragicevic, F. Blaabjerg, and M. Delimar, "Shipboard microgrids: A novel approach to load frequency control," in IEEE Transactions on Sustainable Energy, vol. 9, no. 2, pp. 843-852, Apr. 2018.

[10] M. Faisal, M. A. Hannan, P. J. Ker, A. Hussain, M. B. Mansor, and F. Blaabjerg, "Review of energy storage system technologies in microgrid applications: Issues and challenges," in IEEE Access, vol. 6, pp. 3514335164, 2018.

[11] M. Sandelic, A. Sangwongwanich, and F. Blaabjerg, "A systematic approach for lifetime evaluation of PV-battery systems," in Proceedings of IECON 2019 - 45th Annual Conference of the IEEE Industrial Electronics Society, Lisbon, Portugal, 2019, pp. 2295-2300.

[12] U. Subramaniam, S. Vavilapalli, S. Padmanaban, F. Blaabjerg, J. B. Holm-Nielsen, and D. Almakhles, "A hybrid PV-battery system for ongrid and off-grid applications - controller-in-loop simulation validation," in Energies, vol. 13, no. 3, p. 755, 2020.

[13] N. Mendis, K. M. Muttaqi, S. Perera, and M. N. Uddin, "Remote area power supply system: An integrated control approach based on active power balance," in IEEE Industry Applications Magazine, vol. 21, no. 2, pp. 63-76, Mar.-Apr. 2015.

[14] P. Ariyaratna, K. Muttaqi, and D. Sutanto, "The sizing of battery energy storage for the mitigation of slow and fast fluctuations in rooftop solar PV output," in Proceedings of 2017 IEEE Innovative Smart Grid Technologies-Asia(ISGT-Asia), Auckland, 2017, pp. 1-6.

[15] P. M. Ariyaratna, K. M. Muttaqi, and D. Sutanto, "The simultaneous mitigation of slow and fast voltage fluctuations caused by rooftop solar pv by controlling the charging/discharging of an integrated battery energy storage system," in Journal of Energy Storage, vol. 26, p. 100971, 2019.

[16] S. Koohi-Kamali, N. Rahim, and H. Mokhlis, "Smart power management algorithm in microgrid consisting of photovoltaic, diesel, and battery storage plants considering variations in sunlight, temperature, and load," in Energy Conversation and Management, vol. 84, pp. 562-582, 2014.

[17] M. J. E. Alam, K. M. Muttaqi, and D. Sutanto, "A novel approach for ramp-rate control of solar PV using energy storage to mitigate output fluctuations caused by cloud passing," in IEEE Transactions on Energy Conversion, vol. 29, no. 2, pp. 507-518, Jun. 2014.

[18] N. Kakimoto, H. Satoh, S. Takayama, and K. Nakamura, "Ramp-rate control of photovoltaic generator with electric double-layer capacitor," in IEEE Transactions on Energy Conversion, vol. 24, no. 2, pp. 465-473, Jun. 2009.

[19] S. G. Tesfahunegn, O. Ulleberg, P. J. Vie, and T. M. Undeland, "PV fluctuation balancing using hydrogen storage - a smoothing method for integration of PV generation into the utility grid," in Energy Procedia, vol. 12, pp. 1015-1022, 2011.

[20] A. R. Wilson, "Event triggered analog data acquisition using the exponential moving average," in IEEE Sensors Journal, vol. 14, no. 6, pp. 2048-2055, Jun. 2014.

[21] C. Jamroen, E. Usaratniwart, and S. Sirisukprasert, "PV power smoothing strategy based on heles using energy storage system application: a simulation analysis in microgrids," in IET Renewable Power Generation, vol. 13, no. 13, pp. 2298-2308, 2019.

[22] P. Chanhom, S. Sirisukprasert, and N. Hatti, "Enhanced linear exponential smoothing technique with minimum energy storage capacity for PV distributed generations," in International Review of Electrical Engineering-IREE, vol. 9, pp. 1190-1196, 2014.

[23] K. Koiwa, K. Liu, and J. Tamura, "Analysis and design of filters for the energy storage system: Optimal tradeoff between frequency guarantee and energy capacity/power rating," in IEEE Transactions on Industrial Electronics, vol. 65, no. 8, pp. 6560-6570, Aug. 2017.

[24] M. Datta, T. Senjyu, A. Yona, T. Funabashi, and C.-H. Kim, "Photovoltaic output power fluctuations smoothing methods for single and multiple PV generators," in Current Applied Physics, vol. 10, no. 2, pp. S265-S270, 2010.

[25] H. Liu, J. Peng, Q. Zang, and K. Yang, "Control strategy of energy storage for smoothing photovoltaic power fluctuations," in IFAC-Papersonline, vol. 48, pp. 162-165, 2015.

[26] D. Nikolov, "Power ramp rate reduction in photovoltaic power plants using energy storage," Ph.D. dissertation, Master's Thesis, Aalborg University, Aalborg, Denmark, 2017.

[27] W. A. Omran, M. Kazerani, and M. M. A. Salama, "Investigation of methods for reduction of power fluctuations generated from large gridconnected photovoltaic systems," in IEEE Transactions on Energy Conversion, vol. 26, no. 1, pp. 318-327, Mar. 2010.

[28] Y. Yang, H. Wang, F. Blaabjerg, and T. Kerekes, "A hybrid power control concept for PV inverters with reduced thermal loading," in IEEE Transactions on Power Electronics, vol. 29, no. 12, pp. 6271-6275, Dec. 2014.

[29] F. Blaabjerg, Y. Yang, K. Ma, and X. Wang, "Power electronics - the key technology for renewable energy system integration," in Proceedings of 2015 International Conference on Renewable Energy Research and Applications (ICRERA), Palermo, 2015, pp. 1618-1626.

[30] A. Sangwongwanich, Y. Yang, and F. Blaabjerg, "High-performance constant power generation in grid-connected PV systems," in IEEE Transactions on Power Electronics, vol. 31, no. 3, pp. 1822-1825, Mar. 2016.

[31] Y. Yang, F. Blaabjerg, H. Wang, and M. G. Simões, "Power control 
flexibilities for grid-connected multifunctional photovoltaic inverters," in IET Renewable Power Generation, vol. 10, no. 4, pp. 504-513, 2016.

[32] Q. Xu, H. Wen, Y. Zhu, and X. Li, "An adaptive ramp-rate control for photovoltaic system to mitigate output fluctuation," in 2019 IEEE PES Asia-Pacific Power and Energy Engineering Conference (APPEEC), Macao, 2019, pp. 1-5.

[33] Q. Peng, A. Sangwongwanich, Y. Yang, and F. Blaabjerg, "Grid-friendly power control for smart photovoltaic systems," in Solar Energy, May 2020.

[34] A. Sangwongwanich, Y. Yang, and F. Blaabjerg, "A sensorless power reserve control strategy for two-stagegrid-connected PV systems," in IEEE Transactions on Power Electronics, vol. 32, no. 11, pp. 8559-8569, Nov. 2017.

[35] F. Blaabjerg, A. Sangwongwanich, and Y. Yang, "Flexible power control of photovoltaic systems," in Advancesin Renewable Energies and Power Technologies, pp. 207-229, 2018.

[36] H. D. Tafti, A. Sangwongwanich, Y. Yang, G. Konstantinou, J. Pou, and F. Blaabjerg, "A general algorithm for flexible active power control of photovoltaic systems," in Proceedings of 2018 IEEE Applied Power Electronics Conference and Exposition (APEC), San Antonio, TX, 2018, pp. 1115-1121.

[37] A. Sangwongwanich, Y. Yang, and F. Blaabjerg, "Development of flexible active power control strategies forgrid-connected photovoltaic inverters by modifying MPPT algorithms," in Proceedings of 2017 IEEE 3rd International Future Energy Electronics Conference and ECCE Asia, Kaohsiung, Jun. 2017, pp. 87-92.

[38] A. Sangwongwanich, Y. Yang, and F. Blaabjerg, "A cost-effective power ramp-rate control strategy for single-phase two-stage grid-connected photovoltaic systems," in Proceedings of 2016 IEEE Energy Conversion Congress and Exposition (ECCE), Milwaukee, WI, 2016, pp. 1-7.

[39] X. Li, H. Wen, B. Chen, S. Ding, and W. Xiao, "A cost-effective power ramp rate control strategy based on flexible power point tracking for photovoltaic system," in Solar Energy, vol. 208, pp. 1058-1067, 2020.

[40] X. Chen, Y. Du, H. Wen, L. Jiang, and W. Xiao, "Forecasting-based power ramp-rate control strategies for utility-scale PV systems," in IEEE Transactions on Industrial Electronics, vol. 66, no. 3, pp. 1862-1871, Mar. 2019

[41] X. Chen, Y. Du, and H. Wen, "Forecasting based power ramp-rate control for PV systems without energy storage," in Proceedings of 2017 IEEE 3rd International Future Energy Electronics Conference and ECCE Asia (IFEEC2017-ECCE Asia), Kaohsiung, 2017, pp. 733-738.

[42] E. Cirés, J. Marcos, I. D.L. Parra, M. García, and L. Marroyo, "The potential of forecasting in reducing the lcoe in PV plants under ramp-rate restrictions," in Energy, vol. 188, p. 116053, 2019.

[43] J. Aldersey-Williams and T. Rubert, "Levelised cost of energy-a theoretical justification and critical assessment," in Energy policy, vol. 124, pp. 169-179, 2019.

[44] C. S. Lai and M. D. McCulloch, "Levelized cost of energy for PV and grid scale energy storage systems," [Online]. Available: https://arxiv.org/ pdf/1609.06000.pdf

[45] S. D. Downing and D. Socie, "Simple rainflow counting algorithms," in International Journal of Fatigue, vol. 4, no. 1, pp. 31-40,1982.

[46] E. Schaltz, A. Khaligh, and P. O. Rasmussen, "Influence of battery/ ultracapacitor energy-storage sizing on battery lifetime in a fuel cell hybrid electric vehicle," in IEEE Transactions on Vehicular Technology, vol. 58, no. 8, pp. 3882-3891, Oct. 2009.

[47] H. Beltran, J. Barahona, R. Vidal, J. Alfonso, C. Ariño, and E. Pérez, "Ageing of different types of batteries when enabling a PV power plant to enter electricity markets," in Proceedings of IECON 2016 - 42nd Annual Conference of the IEEE Industrial Electronics Society, Florence, 2016, pp. 1986-1991.

[48] V. Marano, S. Onori, Y. Guezennec, G. Rizzoni, and N. Madella, "Lithium-ion batteries life estimation for plug-in hybrid electric vehicles," in Proceedings of 2009 IEEE Vehicle Power and Propulsion Conference, Dearborn, MI, 2009, pp. 536-543.

[49] M. Safari, M. Morcrette, A. Teyssot, and C. Delacourt, "Life-prediction methods for lithium-ion batteries derived from a fatigue approach I. introduction: Capacity-loss prediction based on damage accumulation," in
Journal of the Electrochemical Society, vol. 157, no. 6, pp. A713-A720, 2010.

[50] H. Beltran, M. Swierczynski, N. Aparicio, E. Belenguer, R. Teodorescu, and P. Rodriguez, "Lithium ion batteries ageing analysis when used in a PV power plant," in Proceedings of 2012 IEEE International Symposium on Industrial Electronics, Hangzhou, 2012, pp. 1604-1609.

[51] J. Dambrowski and S. Pichlmaier, "Mathematical methods for classification of state-of-charge time series for cycle lifetime prediction," in Proceedings of Advanced Automotive Battery Conference Europe, Jun. 2012.

[52] H. Beltran, I. T. García, J. C. Alfonso-Gil, and E. Pérez, "Levelized cost of storage for li-ion batteries used in PV power plants for ramp-rate control," in IEEE Transactions on Energy Conversion, vol. 34, no. 1, pp. 554-561, Mar. 2019.

[53] D. Stroe, M. Świerczyński, A. Stan, R. Teodorescu, and S. J. Andreasen, "Accelerated lifetime testing methodology for lifetime estimation of lithium-ion batteries used in augmented wind power plants," in IEEE Transactions on Industry Applications, vol. 50, no. 6, pp. 4006-4017, Nov.-Dec. 2014.

[54] NREL, "Measurement and instrumentation data center," [Online]. Available: https://midcdmz.nrel.gov

[55] W. Xiao, H. Zeineldin, and P. Zhang, "Statistic and parallel testing procedure for evaluating maximum power point tracking algorithms of photovoltaic power systems," in IEEE Journal of Photovoltaics, vol. 3, pp. 1062-1069, Jul. 2013.

[56] Y. Du, X. Li, H. Wen, and W. Xiao, "Perturbation optimization of maximum power point tracking of photovoltaic power systems based on practical solar irradiance data," in Proceedings of 2015 IEEE 16th Workshop on Controland Modeling for Power Electronics (COMPEL), Vancouver, BC, pp. 1-5, 2015.

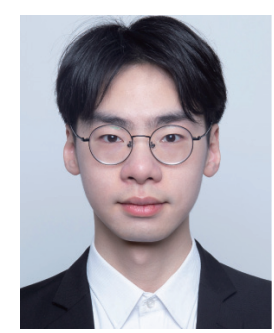

Dingyi Lin received the B.S. degree in electrical engineering and automation from Nanjing Normal University, Nanjing, China, in 2019.

$\mathrm{He}$ is currently pursuing the M.S. degree in electrical engineering from Nanjing Normal University, Nanjing, China. His research interests include renewable energy technology and power forecasting in photovoltaic system.

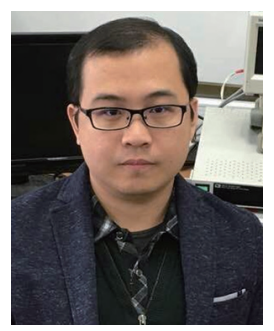

Xingshuo Li received the B.S. degree in computer science from Zhengzhou University, Zhengzhou, China, in 2012, and and the M.S. degree in sustainable energy technology with distinction from Xi'an Jiaotong-Liverpool University, Suzhou, China, in 2015. In 2019, he received the Ph.D. degree from of Liverpool, Liverpool, U.K.

He is currently a Lecturer with School of Electrical and Automation Engineering, Nanjing Normal University, Nanjing, China. His research interests include renewable energy technology and distributed generation, especially ancillary service, power forecasting and fault diagnosis in photovoltaic systems. 


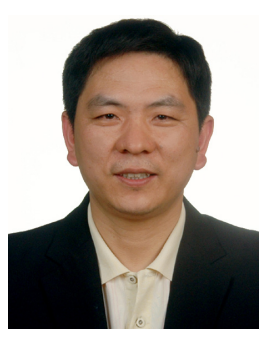

Shuye Ding was born in 1978. He received the B.S., M.S., and Ph.D. degrees in electrical machinery and appliance from Harbin University of Science and Technology, Harbin, in 2001, 2004 and 2008, respectively. He is currently a Professor with the School of Electrical and Automation Engineering, Nanjing Normal University, Nanjing, China. He is the author or coauthor of more than 80 published peerreviewed papers and holds more than 10 patents. His research interests include synthesis physical fields of large electrical machines and theoretical study of special electrical machines.

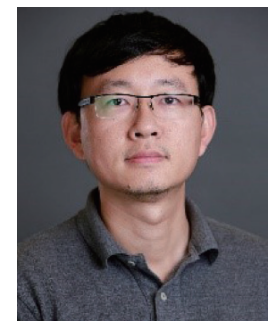

Yang Du received his Ph.D. degree in electrical engineering from the University of Sydney, Australia, in 2013. From 2013 to 2014, he was with Masdar Institute of Science and Technology, Abu Dhabi, UAE, as a post-doctoral research fellow. From 2014 to 2018 , he was a lecturer at Xi'an Jiaotong-Liverpool University, Suzhou, China, where he maintains an honorary position. He joined James Cook University,

Cairns, Australia in 2019. He was a visiting scientist at Massachusetts Institute of Technology in 2018. He is an associate editor of the IET Renewable Power Generation. His research interests include renewable energy integration, power electronics and smart grid. 